\title{
Ultra-thin Metal and Dielectric Layers for Nanophotonic Applications
}

Shkondin, Evgeniy; Leandro, Lorenzo; Malureanu, Radu; Jensen, Flemming; Rozlosnik, Noemi; Lavrinenko, Andrei

\section{Published in:}

Proceedings of ICTON 2015

Link to article, DOI:

10.1109/icton.2015.7193380

Publication date:

2015

Document Version

Peer reviewed version

Link back to DTU Orbit

Citation (APA):

Shkondin, E., Leandro, L., Malureanu, R., Jensen, F., Rozlosnik, N., \& Lavrinenko, A. (2015). Ultra-thin Metal and Dielectric Layers for Nanophotonic Applications. In Proceedings of ICTON 2015 [7193380] IEEE.

https://doi.org/10.1109/icton.2015.7193380

\section{General rights}

Copyright and moral rights for the publications made accessible in the public portal are retained by the authors and/or other copyright owners and it is a condition of accessing publications that users recognise and abide by the legal requirements associated with these rights.

- Users may download and print one copy of any publication from the public portal for the purpose of private study or research.

- You may not further distribute the material or use it for any profit-making activity or commercial gain

- You may freely distribute the URL identifying the publication in the public portal

If you believe that this document breaches copyright please contact us providing details, and we will remove access to the work immediately and investigate your claim 


\title{
Ultra-Thin Metal and Dielectric Layers for Nanophotonic Applications
}

\author{
Evgeniy Shkondin ${ }^{1,2}$, Lorenzo Leandro, ${ }^{1}$ Radu Malureanu ${ }^{1}$, Flemming Jensen ${ }^{2}$, Noemi Rozlosnik, ${ }^{3}$ \\ and Andrei V. Lavrinenko ${ }^{1}$ \\ ${ }^{1}$ Department of Photonics Engineering, Technical University of Denmark, Kongens Lyngby, DK-2800, Denmark \\ ${ }^{2}$ Danish National Center for Micro- and Nanofabrication (DANCHIP), Kongens Lyngby, DK-2800, Denmark \\ ${ }^{3}$ Department of Nanotechnology, Technical University of Denmark, Kongens Lyngby, DK-2800, Denmark \\ Tel: +45 45256352,Fax: +45 45,e-mail: alav@fotonik.dtu.dk
}

\begin{abstract}
In our talk we first give an overview of the various thin films used in the field of nanophotonics. Then we describe our own activity in fabrication and characterization of ultra-thin films of high quality. We particularly focus on uniform gold layers having thicknesses down to $6 \mathrm{~nm}$ fabricated by e-beam deposition on dielectric substrates and Al-oxides/Ti-oxides multilayers prepared by atomic layer deposition in high aspect ratio trenches. In the latter case we show more than 1:20 aspect ratio structures can be achieved.
\end{abstract}

Keywords: ultrathin layers, atomic layer deposition, gold, alumina, titania deposition.

\section{INTRODUCTION}

Ultra-thin films made of metals, semiconductors or dielectrics are on permanent demand for different purposes in modern nanophotonics. Among main research directions where thin films are employed we mention noble metal layers to support surface plasmon polariton propagation in different configurations [1], transparent conductive oxides films for electrodes and for active modulators based on changing the carriers concentration [2,3], and multiple metal-dielectric pairs for hyperbolic metamaterials in the infra-red and visible ranges [4]. Increasing efforts are made in order not only to improve the quality of the deposited layers, but also to diminish their thickness and to find new materials for these fields.

Plasmon optics or plasmonics is currently considered as one of the principle direction of advancing waveguides and interconnects in nanophotonics. It lives through a revival period after its first successful appearance in the 80 -s of the last century. Plasmonics has the full potential to become one of the nanophotonics key instruments to reach extreme light localization, deep subwavelength resolution and enhanced light emission [5]. Such properties stem from light-free electron coupling occurring at metal-dielectric interfaces. The carriers of such interactions are surface plasmons, which occur in two basic configurations: localized surface plasmons with deep analogy in mechanical oscillations and surface plasmon-polaritons (SPPs) or propagating surface plasmons analogous to mechanical waves.

However, the main trade-off of plasmonics was obvious from the very beginning: losses versus confinement. The more the plasmons are confined to the interface the bigger the losses. The latter are conventionally associated with the process of free electrons transport or displacement in metals followed by electron-electron and electron-phonon scattering. Apart from this SPPs loss channel, which exists even in the ideal case of perfectly smooth metal layers interfaces, intensive scattering of surface plasmons on possible surface/bulk imperfections and defects, including the ones of extremely small sizes (of a nanometer scale, like metal grains), add more loss channels. These loss channels are a direct consequence of big wavevectors of SPPs in comparison with light waves of the same frequency [6].

Thus advancing in terms of plasmonic circuitry inevitably brings a challenge of fabricating interfaces as flat as possible. This strict constrain clashes with another requirement - to deposit ultrathin metal layers with typical thicknesses below $20 \mathrm{~nm}$. These two conditions are requested both in plasmonics and metamaterials. In the former the losses of the so-called long range SPPs, considered together with hybrid plasmonic-photonic modes as the workhorse in guiding [7], are inversely dependent on the guiding (metal) layer thickness. In the latter case a new trend in metamaterials claims a metal-dielectric multilayer as the basic device possessing hyperbola-like dispersion bands [8]. In employing such a device as a hyperlens the quality of the lens, e.g. its ability to image subwavelength elements with high contrast is determined by the metal layers thickness and smoothness [9]. Together both requirements impose very high demands for current fabrication technologies implying almost reaching the technological limits of depositing thin layers. Therefore, new advances in the deposition of such layers have to be made.

Another focus area is the fabrication of thin dielectric layers and multilayers. Metal oxides such as $\mathrm{TiO}_{2}$ and $\mathrm{Al}_{2} \mathrm{O}_{3}$ can be used for many different fields of applications including photovoltaic cells, MEMS technology, and high quality dielectrics for DRAM trench capacitors. There is a great need to develop a reliable and reproducible way to pattern such materials on nanoscale. Successful attempts to fabricate and measure two-dimensional photonic crystal based on hexagonal pattering of $\mathrm{TiO}_{2}$ nanopillars with an aspect ratio of 7.5 have been reported [10]. In this work we present a method of fabricating of $\mathrm{TiO}_{2}$ and $\mathrm{Al}_{2} \mathrm{O}_{3}$ high aspect ratio nanogratings on a silicon substrate. 


\section{ULTRATHIN GOLD LAYERS}

Conventionally plasmonic materials are associated with metals. This is because the coupling to free electrons anticipates their presence in excess in a material. From the phenomenological point of view it means that standard solutions of Maxwell's equations for surface waves require different signs of material constants, e.g. permittivity functions, for the media in contact. According to the classical model of the free electron gas, the permittivity is represented by the Drude formula, and the real part of the permittivity is negative below the plasma frequency $\omega_{\mathrm{p}}$. For typical frequencies of the visible and near infra-red (IR) ranges, metals like $\mathrm{Au}, \mathrm{Ag}, \mathrm{Al}$ and $\mathrm{Cu}$ are the best candidates having $\omega_{\mathrm{p}}$ further away in the ultraviolet. However, silver and gold are beyond the list of materials accepted in semiconductor growth processes. $\mathrm{Al}$ and $\mathrm{Cu}$ are CMOS compatible, but in terms of losses are considerable worse compared to gold and especially silver.

Typically thin gold layers are deposited on top of adhesion layers, primarily chromium and titanium. Although they allow for a smooth and thin metal film, neither of these metals is considered by itself as a plasmonic material, therefore the optical characteristics of the whole structure can worsen significantly.

This study analyses the adhesion given by various organosilane chemicals. These organosilanes bind to the silicon surface by hydrolysis and condensation of silane creating covalent bonds on the surface. Linked to the silane end, a carbon chain connects the substrate with a radical. Different radicals were evaluated and their quality as adhesion promoters for gold was analysed. Furthermore, we studied the deposition of various thickness of gold with different deposition rates. We made the latter investigation in order to establish the lower limit for the thickness. The layer quality was investigated using scanning electron microscopy (SEM), atomic force microscopy (AFM) and four-point probe techniques. Although there are tests [11] showing improvement of gold adhesion on silica by using amino-silanes, the limits of Au deposition and a comparison with mercaptosilanes have not yet been investigated. We tested four different chemicals: (3-Mercaptopropyl)trimethoxysilane, $\mathrm{HS}\left(\mathrm{CH}_{2}\right)_{3} \mathrm{Si}\left(\mathrm{OCH}_{3}\right)_{3}, 95 \%$; (3-(2-Aminoethylamino)propyl)trimethoxysilane, $\left(\mathrm{CH}_{3} \mathrm{O}\right)_{3} \mathrm{Si}(\mathrm{CH} 2)_{3} \mathrm{NHCH}_{2} \mathrm{NH}_{2}$, 80\%; (3-Aminopropyl)triethoxysilane, $\mathrm{H}_{2} \mathrm{~N}\left(\mathrm{CH}_{2}\right)_{3} \mathrm{Si}\left(\mathrm{OC}_{2} \mathrm{H}_{5}\right)_{3}, \quad 99 \%$; (3-Aminopropyl)trimethoxysilane, $\mathrm{H}_{2} \mathrm{~N}\left(\mathrm{CH}_{2}\right)_{3} \mathrm{Si}\left(\mathrm{OCH}_{3}\right)_{3}, 97 \%$. For reference, a standard untreated silicon sample was used.

The deposition of gold was made after the chemical treatment using an E-beam evaporation deposition system (deposition pressure $2-4 \times 10^{-6} \mathrm{~Pa}$ ). The Au used has a purity of $99.999 \%$ and was acquired from Kurt J. Lesker ${ }^{\circledR}$. We made several tests to understand how the deposition rate affects the surface quality and how to achieve a complete wetting Au layer with the minimal thickness. We focused in maintaining the deposition rate as stable as possible and we compared the resultant surface only if made during the same process, to reduce the impact of the uncertainty in the deposition. A layer thickness from 4 to $10 \mathrm{~nm}$ and deposition rates from 5 to $13 \AA / \mathrm{s}$ were evaluated [12].
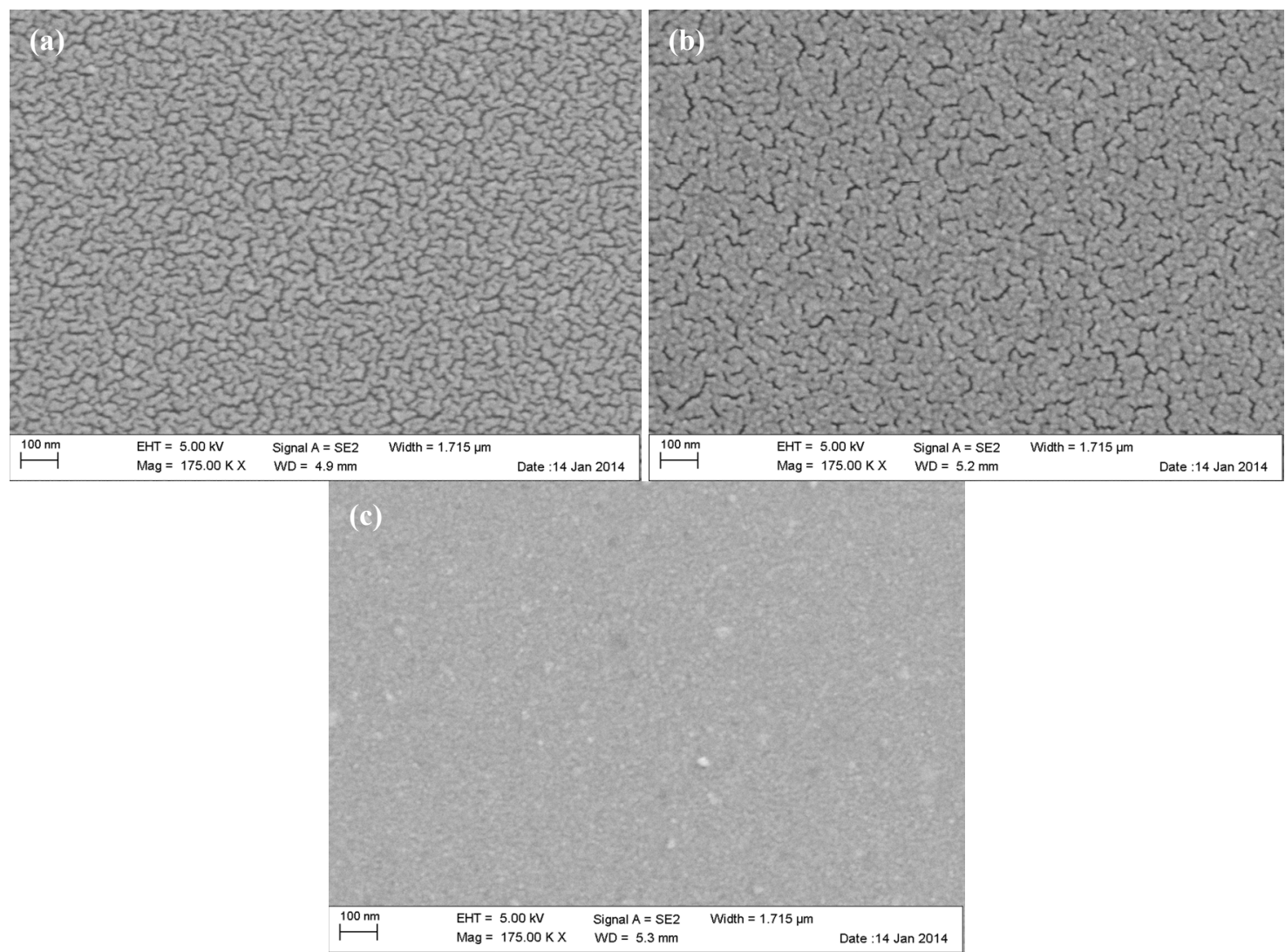

Figure 1. 10nm Au layer deposited on untreated silicon (a) mercaptosilane (b) and aminosilane (c). 
Different silanes were compared with an untreated silicon sample and they proved to act as adhesion promoters. Amino-silanes showed better results compared with Mercapto-silanes (Fig. 1). We showed that the increase in deposition rate improves the surface quality and lower the minimum thickness. The thickness measurement, together with the surface quality check and the four point probe resistivity measurement, demonstrated that it is possible to deposit a good-quality gold layer of thickness as low as $5 \mathrm{~nm}$. Finally, roughness measurements showed low average roughness below $0.2 \mathrm{~nm}$ with $0.3 \mathrm{~nm}$ RMS.

\section{DIELECTRIC MULTILAYERS}

As a starting point deep UV lithography was used to pattern resist on $2 \mathrm{~cm}^{2}$ scale chips. Thereafter deep reactive ion etching was used to fabricate $4.5 \mu \mathrm{m}$ deep silicon trenches with the period of $400 \mathrm{~nm}$ (the aspect ratio is more than 20). The silicon trenches were coated using atomic layer deposition (ALD) with $100 \mathrm{~nm}$ thick $\mathrm{TiO}_{2}$ or $\mathrm{Al}_{2} \mathrm{O}_{3}$ at $150^{\circ} \mathrm{C}$ (Fig. 2). ALD coatings forms nanostructured gratings but in order to isolate them it is necessary to remove the silicon. The etching of the top part of the $\mathrm{TiO} 2$ coating was done using inductively coupled plasma reactive ion etching (ICP) with chlorine chemistry. It insures anisotropic etching and, as such, it is possible to remove the top part of the $\mathrm{TiO}_{2}$ coating keeping the sidewalls and the bottom unharmed. The selective removal of $\mathrm{TiO}_{2} / \mathrm{Al}_{2} \mathrm{O}_{3}$, grants access to the Si-core between the coatings. Finally, using fluorine chemistry in the ICP the Si-core was removed selectively without any observable influence on $\mathrm{TiO}_{2}$ or $\mathrm{Al}_{2} \mathrm{O}_{3}$ revealing extremely high selectivity throughout the fabrication (see insets in Fig. 2 for detailed view).

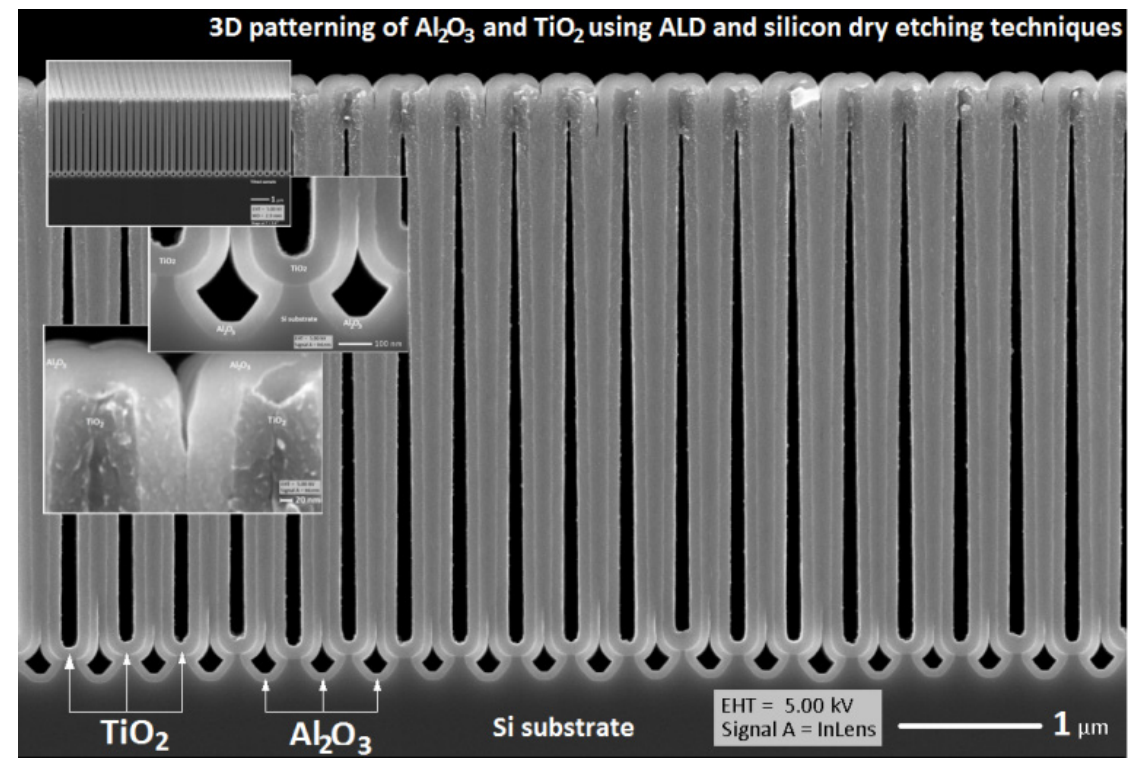

Figure 2. Fabrication of $\mathrm{TiO}_{2}$ and $\mathrm{Al}_{2} \mathrm{O}_{3}$ nanogratings. Isolating $\mathrm{TiO}_{2}$ or $\mathrm{Al}_{2} \mathrm{O}_{3}$ by removing the silicon core leads to the formation of nanostructured gratings.

\section{CONCLUSIONS}

The definition of ultra-smooth, ultra-thin layers is subjected to the functionality of a concrete device or an operational frequency range. Thus, what can be ultra-smooth in one case can be extremely rough in another. Here, we have reported on the techniques for fabricating gold layers that can be considered extremely smooth for visible and infra-red radiation thus aiming at the average roughness below $1 \mathrm{~nm}$ and layers thicknesses ideally below $10 \mathrm{~nm}$. Such layers would allow for lower losses in devices that are based on plasmon propagation and localisation or metal-dielectric metamaterial performance thus helping in pushing plasmonic-based devices towards the market.

Also we showed that extremely high aspect ratio trenches made from titania and/or alumina can be fabricated using ALD. Such structures can be used in designs, where pronounced anisotropy is required, for example, for observation of Dyakonov surface waves.

\section{REFERENCES}

[1] S.I. Bozhevolnyi, Plasmonic Nanoguides and Circuits, 2008.

[2] N. Kinsey et al.: Examining nanophotonics for integrated hybrid systems: A review of plasmonic interconnects and modulators using traditional and alternative materials, J. Opt. Soc. Am. B, vol. 32, pp. 121-142, Dec. 2014. 
[3] V.E. Babicheva, A. Boltasseva, and A.V. Lavrinenko: Transparent conducting oxides for electro-optical plasmonic modulators, Nanophotonics, in press.

[4] Ting S. Luk et al:: Near-infrared surface plasmon polariton dispersion control with hyperbolic metamaterials, Opt. Express, vol.21, pp.11107-11114, 2013.

[5] R. Soref: The past, present, and future of silicon photonics, IEEE J. Sel. Top. Quantum Electron., vol. 12, pp. 1678-1687, Nov. 2006.

[6] V.J. Logeeswaran, M.-L. Chan, Y. Bayam, M. Saif Islam, D.A. Horsley, X. Li, W. Wu, S.Y. Wang, and R.S. Williams: Ultra-smooth metal surfaces generated by pressure-induced surface deformation of thin metal films, Appl. Phys. A, vol. 87, pp. 187-192, Jan. 2007.

[7] P. Berini: Long-range surface plasmon polaritons, Adv. Opt. Photonics, vol. 1, p. 484, Sep. 2009.

[8] M.A. Noginov, Y.A. Barnakov, G. Zhu, T. Tumkur, H. Li, and E.E. Narimanov: Bulk photonic metamaterial with hyperbolic dispersion, Appl. Phys. Lett., vol. 94, 151105, Apr. 2009.

[9] O. Kidwai, S.V. Zhukovsky, and J.E. Sipe: Effective-medium approach to planar multilayer hyperbolic metamaterials: Strengths and limitations, Phys. Rev. A, vol. 85, 053842, May 2012.

[10] Y. Huang et al.:: The atomic layer deposition array defined by etch-back technique: A new method to fabricate TiO2 nanopillars, nanotubes and nanochannel arrays, Nanotechnology, vol. 23, 485306, 2012.

[11] D. Petri et al.: An improved method for the assembly of amino-terminated monolayers on $\mathrm{SiO}_{2}$ and the vapor deposition of gold layers, Langmuir, vol.15, pp.4520-4523, 1999.

[12] L. Leandro et al.: Ultrathin, ultrasmooth gold layer on dielectrics without the use of additional metallic adhesion layers, ACS Applied Materials \& Interfaces, vol.7, pp. 5797-5802, 2015. 